\title{
Assessment of vitamin D levels in zona zoster
}

\author{
göktürk dere ${ }^{1}$ and Murat Ozturk ${ }^{2}$ \\ ${ }^{1}$ Affiliation not available \\ ${ }^{2}$ Hlth Sci Univ
}

June 8, 2021

\begin{abstract}
Aim: Vitamin D affects the secretion of antimicrobial peptides associated with toll-like receptor (TLR), which have antiviral effects. It has been suggested that vitamin D may affect the susceptibility of the host to varicella zoster virus (VZV) and the clinical course of zona zoster. Materials and Methods: In this study, 101 patients who were diagnosed with zona zoster at the dermatology outpatient clinic and had a vitamin D result at the time of diagnosis and a control group of 100 people were included. Results were analyzed statistically. Results: The 25-OH vitamin D levels of the patients ranged from 2.37 to 32.98 $\mu \mathrm{g} / \mathrm{L}$ and the mean value was $14.25 \pm 7.20 \mu \mathrm{g} / \mathrm{L}$. In the control group, 25-OH vitamin D levels ranged between 10.3 and $44.25 \mu \mathrm{g} / \mathrm{L}$, and the mean value was $24.9 \pm 6.24 \mu \mathrm{g} / \mathrm{L}$. 25-OH vitamin D levels in the patient group were significantly lower than the levels in the control group. $(\mathrm{p}<0.001)$ Conclusion: This study revealed that $25-\mathrm{OH}$ vitamin $\mathrm{D}$ levels were significantly lower in patients with zona zoster compared to the control group. 25-OH vitamin D deficiency may increase the risk of VZV reactivation, and vitamin D supplementation in patients with vitamin D deficiency in zona zoster may help the mild course of the disease.
\end{abstract}

\section{Assessment of vitamin D levels in zona zoster}

\section{ABSTRACT}

Aim: Vitamin D affects the secretion of antimicrobial peptides associated with toll-like receptor (TLR), which have antiviral effects. It has been suggested that vitamin D may affect the susceptibility of the host to varicella zoster virus (VZV) and the clinical course of zona zoster.

Materials and Methods : In this study, 101 patients who were diagnosed with zona zoster at the dermatology outpatient clinic and had a vitamin D result at the time of diagnosis and a control group of 100 people were included. Results were analyzed statistically.

Results: The $25-\mathrm{OH}$ vitamin D levels of the patients ranged from 2.37 to $32.98 \mu \mathrm{g} / \mathrm{L}$ and the mean value was $14.25 \pm 7.20 \mu \mathrm{g} / \mathrm{L}$. In the control group, 25-OH vitamin D levels ranged between 10.3 and $44.25 \mu \mathrm{g} / \mathrm{L}$, and the mean value was $24.9 \pm 6.24 \mu \mathrm{g} / \mathrm{L}$. $25-\mathrm{OH}$ vitamin $\mathrm{D}$ levels in the patient group were significantly lower than the levels in the control group. $(\mathrm{p}<0.001)$

Conclusion: This study revealed that $25-\mathrm{OH}$ vitamin $\mathrm{D}$ levels were significantly lower in patients with zona zoster compared to the control group. 25-OH vitamin D deficiency may increase the risk of VZV reactivation, and vitamin $\mathrm{D}$ supplementation in patients with vitamin $\mathrm{D}$ deficiency in zona zoster may help the mild course of the disease.

Keywords: Zona zoster; Vitamin D; Varicella zoster virus

\section{What is already known about this topic?}

It has been found that vitamin D deficiency is frequently seen in those who have had various viral infectious diseases. Data on the association between zona zoster and vitamin D are limited in the literature. 


\section{What does this article add?}

25-OH vitamin $\mathrm{D}$ deficiency may predispose to zona zoster disease, and vitamin $\mathrm{D}$ supplementation in patients with vitamin D deficiency may help this disease to be mild course.

\section{INTRODUCTION}

Zona zoster is a painful disease with dermatomal localized vesicles. It is a disease that can cause significant acute morbidity and long-term sequelae, including chronic pain, which can seriously impair the quality of life even in those receiving appropriate antiviral therapy. Zona zoster occurs following a decrease in cellmediated immunity specific to varicella zoster virus (VZV), and therefore the risk of zona zoster among individuals with impaired cell-mediated immune function is increased [1,2]. The most important risk factor for zona zoster is advanced age. Aging reduces the skin's ability to synthesize vitamin D, and increased skin pigmentation reduces the effectiveness of UVB to stimulate vitamin D synthesis [3,4].

Cell mediated immunity is known to decrease with age, and decreased cell mediated immunity is associated with reactivation of VZV [5]. Vitamin D is important for calcium homeostasis, bone health, and prevention of fractures. Vitamin D has effects on metabolic, neoplastic, inflammatory, and immune events [6,7]. Vitamin $\mathrm{D}$ deficiency is considered to be a serum 25-hydroxyvitamin D (25-OH-D) level of less than $20 \mathrm{ng} / \mathrm{ml}$. 25-OH-D vitamin values between 20 and $30 \mathrm{ng} / \mathrm{ml}$ are considered insufficient and are considered clinically important. The prevalence of vitamin D deficiency varies according to geographic regions with different levels of sunlight exposure [7,8]. It has been found that vitamin D deficiency is frequently seen in various viral infectious diseases. Vitamin $\mathrm{D}$ affects the secretion of antimicrobial peptides associated with several toll-like receptors (TLRs) that have antiviral effects. Similarly, $1,25-(\mathrm{OH})^{2}$-D strongly stimulated the release of human cathelicidins from neutrophils and possibly monocytes and natural killer cells. Human cathelicidin is induced by TLR1 / 2 activation and contributes to mucosal immunity and provides antiviral effects $[7,8]$. There are few publications on the relationship between vitamin $\mathrm{D}$ levels and zona zoster. Chao et al. suggested that vitamin D may affect both human susceptibility to varicella zoster virus and the clinical course of zona zoster [8].

In this study, we aimed to compare the vitamin D level in zona zoster patients with that of healthy controls and to investigate the possible role of vitamin D level in the development of zona zoster.

\section{MATERIALS AND METHODS}

Local ethics committee approval was obtained for the study. In this study, 101 patients who applied to Ordu State Hospital dermatology outpatient clinic between March 2019 and June 2020 and were diagnosed with zona zoster and had a vitamin D result at the time of diagnosis and a control group of 100 people were included. Data of the patient and control groups were recorded. The location of the disease and the season of admission were recorded in the patient group. Individuals with cardiovascular disease, gastrointestinal disease, kidney disease, malignancy, pregnancy, diabetes mellitus, autoimmune and inflammatory diseases, and individuals taking vitamin D supplements were not included in the control group. Informed consent was obtained.

The data were evaluated with IBM SPPS statistics 21 package program. Numerical variables were expressed as mean \pm standard deviation, percentage. An evaluation was made after checking whether the parameters were normally distributed. In data analysis, student's T test was used for group comparisons, and in cases where there was no normal distribution, Mann Whitney-U test was used. The relationship between the two variables was evaluated using the Pearson correlation test in parametric tests and the Spearman correlation test in non-parametric tests. A value of $\mathrm{p}<0.05$ was accepted for the significance level of the tests.

\section{RESULTS}

Of the 101 patients included in the study, 57 (56.4\%) were female and $44(43.4 \%)$ were male. The ages of the patients ranged from 18 to 77 , and the mean age was $49.72 \pm 16.37 .64$ (64\%). Of the 100 patients in the control group, $64(64 \%)$ were female and $36(36 \%)$ were male. The ages of the control group ranged from 
18 to 78 years, with a mean age of $49.16 \pm 17.61$. There was no significant difference between the patient group and the control group in terms of age and gender $(\mathrm{p}=0.83)$.

Thirty five $(34.7 \%)$ of the zona zoster patients applied to the outpatient clinic in winter, 5 (5\%) in spring, 30 $(29.7 \%)$ in summer and $31(30.7 \%)$ in autumn. Zona zoster developed in the thoracic region in 42 patients, in the lumbar region in 31 patients, in the ophthalmic region in 7 patients, in the leg region in 10 patients, in the arm region in 2 patients, in the cervical region in 8 patients, and in the mandibular region in 1 patient (Table 1).

25-OH vitamin D levels were calculated as $<20 \mu \mathrm{g} / \mathrm{L}$ deficiency, 21-29 $\mu \mathrm{g} / \mathrm{L}$ insufficiency and $>30 \mu \mathrm{g} / \mathrm{L}$ sufficient dose. The $25-\mathrm{OH}$ vitamin D levels of the patients ranged from 2.37 to $32.98 \mu \mathrm{g} / \mathrm{L}$ and the mean value was $14.25 \pm 7.20 \mu \mathrm{g} / \mathrm{L}$. In the patient group, the number of patients with deficiency of 25-OH vitamin D level was $82(81.2 \%)$, the number of patients with insufficient level was $15(14.9 \%)$, and the number of patients with sufficient level was $4(4 \%)$. In the control group, 25-OH vitamin D levels ranged between 10.3 and $44.25 \mu \mathrm{g} / \mathrm{L}$, and the mean value was $24.9 \pm 6.24 \mu \mathrm{g} / \mathrm{L}$. In the control group, the number of individuals with 25-OH vitamin D deficiency was $20(20 \%)$, the number of individuals with insufficient level was $59(59 \%)$, and the number of individuals with sufficient level was 21 (21\%). 25-OH vitamin D levels in the patient group were significantly lower than the levels in the control group ( $\mathrm{p}<0.001)$ (Table 2 ).

\section{DISCUSSION}

Zona zoster is more common in women than men. Thoracic, lumbar, trigeminal and cervical dermatomes are the most frequently affected areas [3]. In our study, the most affected dermatomes were thoracic and lumbar dermatomes, respectively.

With advanced age, the risk of developing shingles more severely increases as a result of the decrease in the immune response specific to varicella zoster virus in people with immunosuppressive disease or drug use $[1,3,9]$. In humans, the main source of vitamin D is UVB-mediated synthesis in the skin. Certain foods, such as fatty fish and dairy products, contain vitamin D. Vitamin D activation involves two hydroxylation steps, one in the liver and the other in the kidney. In particular, final activation of vitamin D by 1-alpha hydroxylase also occurs in extra kidney tissues, including epithelial and immune cells [10].

The determination of the vitamin D receptor in peripheral blood mononuclear cells has led to an emphasis on the regulatory role of vitamin $\mathrm{D}$ in the immune system [6,11]. $25(\mathrm{OH})$-Vitamin $\mathrm{D}$ enters the monocyte and, after being converted to $1,25-(\mathrm{OH})^{2}$-D in the mitochondria, binds to the vitamin $\mathrm{D}$ receptor (VDR) and ultimately acts as a transcription factor for human cathelicidin, an antimicrobial peptide. Defensins can also inhibit viral replication and cause direct degradation of the viral membrane [12]. After pathogen exposure, monocytes and macrophages increase the number of vitamin D receptors to increase cathelicidin production $[13,14]$. Cathelicidin effectively inhibits herpes simplex virus type 1 and retrovirus replication in LL-37 peptide form. In addition, severe $1,25-(\mathrm{OH})^{2}$-D deficiency has been associated with clinically advanced human immunodeficiency virus (HIV) infection, and vitamin D supplementation significantly inhibits hepatitis C virus (HCV) proliferation [7]. B cells infected with Epstein-Barr virus (EBV) exhibit significantly lower levels of VDR expression compared to uninfected cells [7]. Activation of $\mathrm{B}$ and $\mathrm{T}$ lymphocytes has been shown to result in VDR expression. In addition, 1,25- $(\mathrm{OH})^{2}$-D stimulates T lymphocyte maturation, increases the regulatory $\mathrm{T}$ lymphocyte ratio, and plays a role in limiting inflammation triggered by microbial invasion [6,13]. HIV infection weakens VDR activity. The decrease in VDR expression or activity levels leads to the impairment of innate immunity, thus allowing intracellular pathogens such as viruses to remain. However, vitamin D itself exhibits antiviral effects in vitro [7]. In a study of the effects of vitamin D-related antimicrobial peptides on herpes viruses, cathelicidine was shown to reduce HSV-1 viral titers isolated from patients with keratoconjunctivitis [13]. It has been shown that vitamin D deficiency correlates with increased mental stress. Stress can affect the activation of CD8 + T lymphocytes through the induction of neuroendocrine factors that regulate the transition between viral latency and reactivation in neurons. In this way, vitamin D deficiency causes the weakening of immunity and predisposes to the development of zona [7]. In a study of patients undergoing dialysis for chronic kidney failure, it was found that the risk of zona reactivation was 
significantly lower in patients who received vitamin D supplements [6]. Chao et al. suggested that vitamin D may also play a role in controlling VZV replication during zona zoster management, as the control of most episodes of viral infection depends on cell-mediated immunity and related cytokines [7]. Vitamin D can inhibit neuroinflammation through down-regulation of pro-inflammatory cytokines and up-regulation of anti-inflammatory cytokines. Chen et al. showed in their study that hypovitaminosis D was significantly higher in postherpetic neuralgia patients compared to controls [15]. In a study by Han et al. with 30 zoster patients, the incidence of herpes zoster decreased as 25 hydroxyvitamin D3 increased [16]. In our study, $25-(\mathrm{OH})-\mathrm{D}$ vitamin levels were found to be lower in patients with zona zoster than in the control group.

A cohort study concluded that while low vitamin D levels were associated with a higher risk of progression to AIDS in HIV-infected patients, vitamin D supplementation did not affect mortality, CD4 cell count, and viral load [13]. Chao et al found that both serum total and bioavailable vitamin D levels were positively associated with zoster antibody levels [7].

In a study conducted in Canada, low 25-OH-vitamin D levels were associated with an increased risk of viral upper respiratory tract infections in children [17]. In another study by Sabetta et al, including healthy adults, it was found that those with 25-OH-D vitamin over $38 \mathrm{ng} / \mathrm{ml}$ had a lower risk of acute viral respiratory tract infection [18]. In a meta-analysis by Bergman et al., vitamin D supplementation was found to have a protective effect against respiratory tract infections [10].

The fact that our study was retrospective and the clinical course and complications of disease could not be evaluated are among the limitations of our study. This study revealed that $25-\mathrm{OH}$ vitamin $\mathrm{D}$ levels were significantly lower in zona zoster patients compared to the control group. 25-OH vitamin D deficiency may increase the risk of VZV reactivation, and vitamin D supplementation in patients with vitamin D deficiency in zona zoster may help mild and reduce the disease and complications such as postherpetic neuralgia. Controlled prospective studies are needed on this subject.

\section{Author Contributions}

GD designed the study, collected data, conducted literature search and wrote the manuscript. MO participated in literature search, performed analysis, read and approved the manuscript.

\section{Acknowlegments}

None.

\section{Financial disclosure}

No conflict of interest was declared by the authors.

\section{Conflict of interest}

No conflict of interest was declared by the authors.

\section{REFERENCES}

1. Kawai K, Gebremeskel BG, Acosta CJ. Systematic review of incidence and complications of herpes zoster: towards a global perspective. BMJ Open. 2014;4(6):e004833.

2. Thomas SL, Wheeler JG, Hall AJ. Micronutrient intake and the risk of herpes zoster: a case-control study. Int J Epidemiol. 2006;35(2):307-14.

3. Cohen JI. Clinical practice: Herpes zoster. N Engl J Med. 2013;369(3):255-63.

4. Cashman KD, Dowling KG, Skrabakova Z, Gonzalez-Gross M, Valtuena J, et al. Vitamin D deficiency in Europe: pandemic? Am J Clin Nutr. 2016;103:1033-44

5. Gershon AA, Gershon MD, Breuer J, Levin MJ, Oaklander AL, Griffiths PD. Advances in the understanding of the pathogenesis and epidemiology of herpes zoster. J Clin Virol . 2010;48 Suppl 1(Suppl 1):S2-S7.

6. Chao CT, Lee SY, Yang WS, Yen CJ, Chiang CK, Huang JW, Hung KY. Serum vitamin D levels are positively associated with varicella zoster immunity in chronic dialysis patients. Sci Rep. 2014;4:7371. 
7. Chao CT, Chiang CK, Huang JW, Hung KY. Vitamin D is closely linked to the clinical courses of herpes zoster: From pathogenesis to complications. Med Hypotheses. 2015;85(4):452-7.

8. Holick MF, Chen TC. Vitamin D deficiency: a worldwide problem with health consequences. Am J Clin Nutr. 2008;87(4):1080S-6S.

9. Gnann JW Jr, Whitley RJ. Clinical practice. Herpes zoster. N Engl J Med. 2002;347(5):340-6.

10. Bergman P, Lindh AU, Björkhem-Bergman L, Lindh JD. Vitamin D and Respiratory Tract Infections: A Systematic Review and Meta-Analysis of Randomized Controlled Trials. PLoS One. 2013;8(6):e65835.

11. Cantorna MT, Yu S, Bruce D. The paradoxical effects of vitamin D on type 1 mediated immunity. Mol Aspects Med. 2008;29(6):369-75.

12. Gois PHF, Ferreira D, Olenski S, Seguro AC. Vitamin D and Infectious Diseases: Simple Bystander or Contributing Factor? Nutrients. 2017;9(7):651.

13. Lin LY, Bhate K, Forbes H, Smeeth L, Warren-Gash C, Langan S. Vitamin D deficiency or supplementation and the risk of human herpesvirus infections or reactivation: a systematic review protocol. BMJ Open. 2019;9(10):e031867.

14. Thornton KA, Marín C, Mora-Plazas M, Villamor E. Vitamin D deficiency associated with increased incidence of gastrointestinal and ear infections in school-age children. Pediatr Infect Dis J. 2013;32(6):58593.

15. Chen JY, Lin YT, Wang LK, et al. Hypovitaminosis Din Postherpetic Neuralgia-High Prevalence and Inverse Association with Pain: A Retrospective Study. Nutrients. 2019;11(11):2787. Published 2019 Nov 15.

16. Han G, Choi Y, Lee K, Park Y, Cho S, Shim M, Kim B, Kim S. The Comparison of the Blood Level of 25-Hydroxyvitamin $\mathrm{D}_{3}$ in Healthy Adult and Patients with Herpes Zoster. KJFP 2016;6:288-292.

17. Science M, Maguire JL, Russell ML, Smieja M, Walter SD, Loeb M. Low serum 25-hydroxyvitamin D level and risk of upper respiratory tract infection in children and adolescents. Clin Infect Dis. 2013;57(3):392-7.

18. Sabetta JR, DePetrillo P, Cipriani RJ, Smardin J, Burns LA, Landry ML. Serum 25-hydroxyvitamin D and the incidence of acute viral respiratory tract infections in healthy adults. PLoS One 2010; 5:e11088.

Table 1. Zona zoster distribution

\begin{tabular}{clll}
\hline Localisation & & Number $(\mathbf{n}=)$ & Percent $\mathbf{( \% )}$ \\
\hline & Thoracal & 42 & 41,6 \\
Lumbar & 31 & 30,7 \\
& Ophthalmic & 7 & 6,9 \\
& Leg & 10 & 9,9 \\
Arm & 2 & 2,0 \\
& Cervical & 8 & 7,9 \\
Mandibular & 1 & 1,0 \\
Total & 101 & 100,0 \\
\hline
\end{tabular}

Table 2. Comparison of 25-OH vitamin D levels of groups

\begin{tabular}{lll}
\hline & Patient Group & Control Group \\
\hline $\begin{array}{l}\text { 25-OH D vitamin levels } \\
\text { ( } \boldsymbol{Y r} / \boldsymbol{\Lambda})\end{array}$ & $14,25 \pm 7,20$ & $24,9 \pm 6,24$ \\
Age (Year) Gender & $49,72 \pm 16,3757$ female 44 male & $49,16 \pm 17,6164$ female 36 male \\
25-OH D vitamin deficiency & $\mathrm{n}=82$ & $\mathrm{n}=20$ \\
$\begin{array}{l}\text { 25-OH D vitamin } \\
\text { insufficiency }\end{array}$ & $\mathrm{n}=15$ & $\mathrm{n}=59$ \\
\end{tabular}




\begin{tabular}{lll}
\hline & Patient Group & Control Group \\
\hline 25-OH D vitamin adequate & $\mathrm{n}=4$ & $\mathrm{n}=21$ \\
\hline
\end{tabular}

